\title{
The Effect of Orem Self-care Model with a Focus on Systematic Medicine Usage on the Hypertension of the EIderly
} Ghasem Niai Namaghi Sh${ }^{1}$, *Ahmadi F², Taheri Tanjani $\mathrm{P}^{3}$, Qolami Fesharaki $\mathrm{M}^{4}$

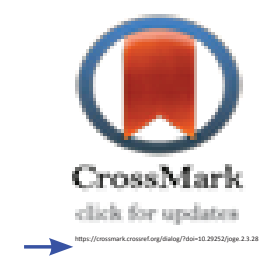

1- MSc Student of Nursing, Nursing Department, Faculty of Medical Sciences, Tarbiat Modares University, Tehran, Iran.

2- Professor, Nursing Department, Faculty of Medical Sciences, Tarbiat Modares University, Tehran, Iran (Corresponding Author)

E-mail: ahmadif@modares.ac.ir

3- Assistant Professor, Faculty of Medical Sciences and Health Services, Shahid Beheshti, Tehran, Iran.

4- Assistant Professor, Department of Biostatistics, Faculty of Medical Sciences, Tarbiat Modares University, Tehran, Iran.

\section{Abstract}

Introduction: Hypertension is one of the most common diseases in the elderly. Systematic use of medicine due to the polypharmacy phenomenon can be effective in controlling hypertension in the elderly. Therefore, self-care in systematic use of medicine of this group is crucial. The aim of this study was to determine the effect of Orem Self-care Model with a focus on systematic medicine usage, on the elderly infected by hypertension.

Method: The present study is a quasi-experimental study in eldely in Tehran in 2015 . The data collection was conducted using a barometer that is calibered and blood pressure was controlled by researcher. Sixty patients were selected using non-randomly and available method from elderly clinic in Taleghani hospital. After the pre-test, 4 training sessions were conducted based on the need assessment and using the Orem Model. Then, the post-tests were performed one and three months after the intervention. Data analysis was performed using the SPSS 21 Software, and Mann-Whitney and Wilcoxon tests.

Results: According to the Chi-square test, the samples of the two groups were identical in terms of demographic variables $(\mathrm{P}<0.05)$. After the intervention in the test group, there was a significant statistical difference in the self-care ability and control of hypertension of the elderly $(\mathrm{P}=0 / 000)$; while, the difference was not significant in the control group $(\mathrm{P}=0 / 53)$.

Conclusion: The results show that the application of Orem Self-care Model with a focus on systematic medicine usage is efficient on the elderly affected by hypertension. It is suggested that Orem Self-care Model with a focus on systematic medicine usage, to be considered for other diseases.

Keywords: Hypertension, Elderly, Systematic Medicine Usage, Orem Self-Care Model.

Received: $24 / 01 / 2018$

Accepted: 23/02/2018

\begin{tabular}{|l|l|}
\hline \multicolumn{3}{|c|}{ Access this article online } \\
\hline
\end{tabular}




\section{تأثير مدل خودمر اقبتى اورم با محوريت مصرف اصولى داروها بر بر فشارى خون سالمندان

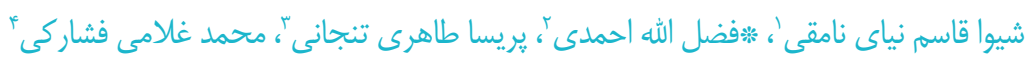

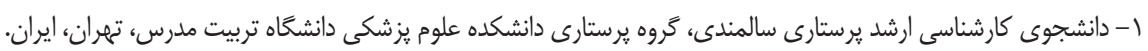

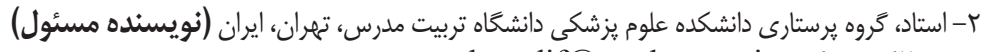
يست الكترونيكى: ahmadif@modares.ac.ir

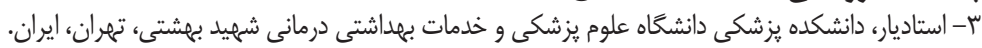

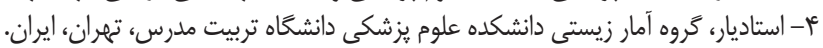

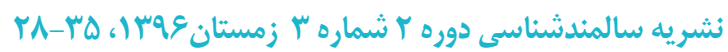

مقدمه: يرفشارى خون يكى از بيمارى هاى بسيار شايع در دوران سالمندى است. مصرف اصولى داروها با توجه به يديده يلى فارمسى

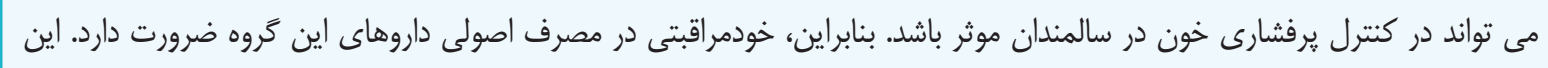

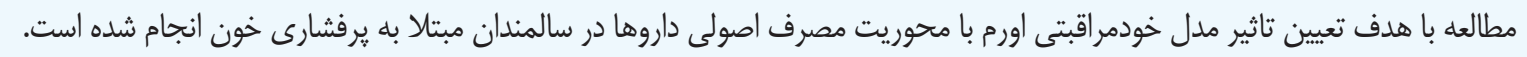

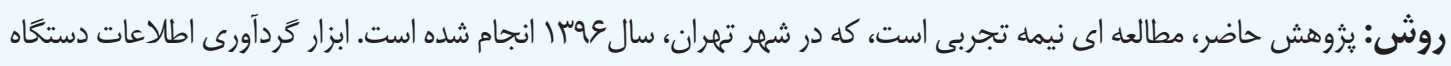

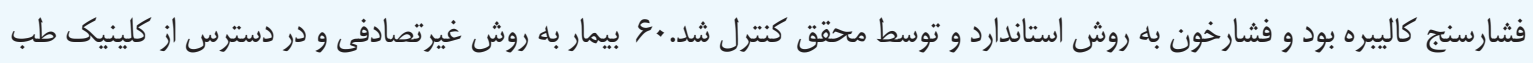

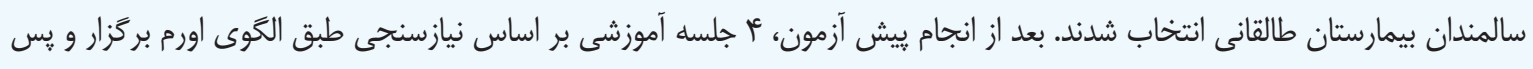

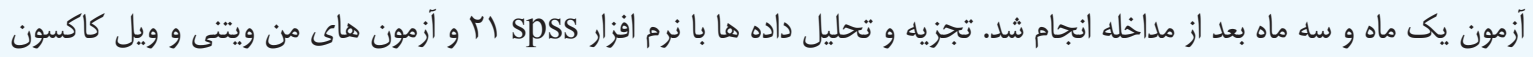

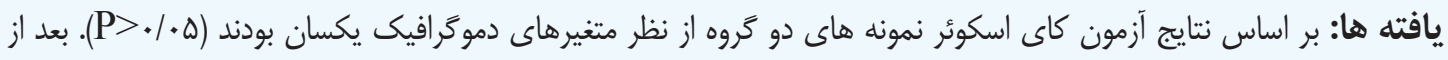

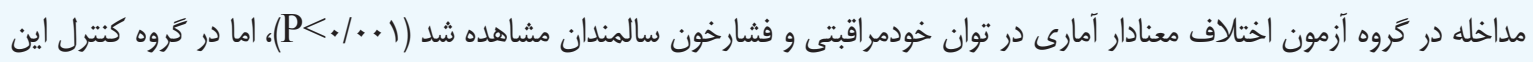

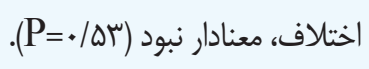

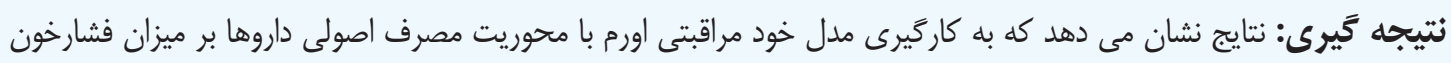

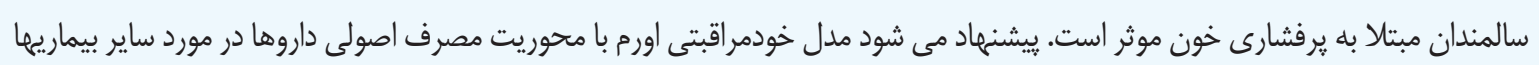
به كار گرفته شود. كليد وازهه ها: يرفشارى خون، سالمندان، مصرف اصولى داروها، مدل خودمراقبتى اورم.

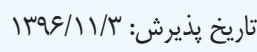

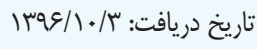


رابطه معنادارى را بين خودمراقبتى و ارتقاى سلامتى در سالمندان يرتغالى يافتند (19). در ايران سليمى و همكاران (ها. (r) در مطالعه اى كه بر روى سالمندان شهر زنجان انجام دادند، دريافتند ارتقاى باى

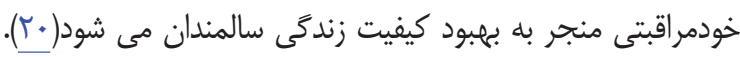
بنابراين مى توان بيان كرد كه رفتارهاى خودمراقبتى منجر به بهبع ديود زندگى در ابعاد مختلف زندگى سالمندان مى شود و يزوهش هاى

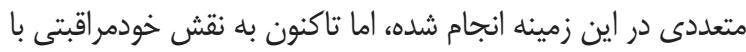

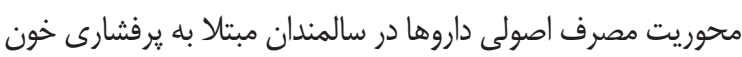
برداخته نشده است. بنابراين با توجه به كمبود تحقيقات انجام شده در درد

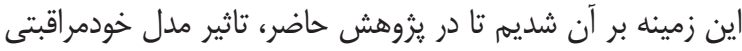

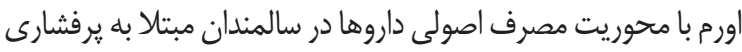

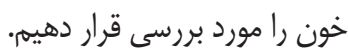

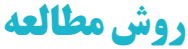

يزوهش حاضر، مطالعه ایى نيمه تجربى از نوع ييش آزمون -

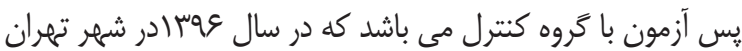
انجام شده و مداخله در آن شامل به كاركَيرى الكَى اورم با محوريت

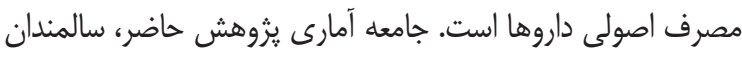

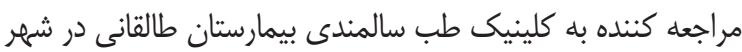
تهران مى باشد. حجم نمونه با توجه به تحقيقات قبلى و با توان

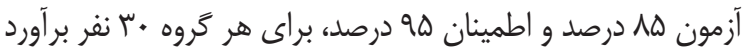
شد. نمونه گَيرى به روش غير تصادفى و در دسترس و تخصيص نمونه ها در دو تروه به صورت تصادفى بود. معيارهاى ورود به مطالعه شامل سن بين •و تا •م سال، سواد خواندن و نوشتن، زبان فارسى، داشتن سابقه برفشارى خون و تحت ستان درمان با داروهاى ضدفشارخون بودن و معيار خروج عدم علاقمندى زيان

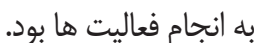
ابزار گَردآورى داده ها، در اين يزوهش شامل يرسشنامه اطلاعات دموگرافيك (جنس، سن، وزن، قد، وضعيت تاهل، تحصيلات، شغل، تعداد فرزندان، كفايت درآمد، حمايت مالى، محل زندگىى، فعاليت فيزيكى، انجام امور مراقبتى، ابتلا به بيمارى ها، سابقه مصرف سيعار، حساسيت دارويى يا غذايى، داروهاى مصرفى)

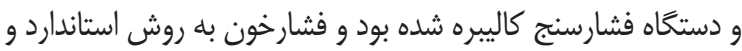
توسط يك فرد (محقق) كنترل شد. يس إز تكميل يرسشنامه ها و كنترل فشار خون در سه روز

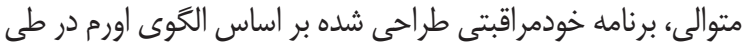

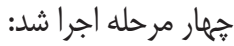
ا- ارزيابى نيازهاى خودمراقبتى در واحدهاى مورد مطالعه و

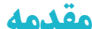

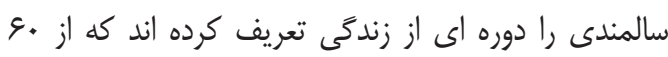

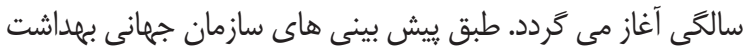

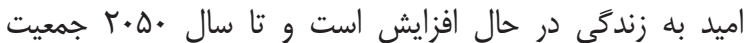

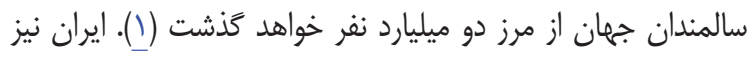

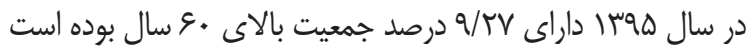
(T). با افزايش سن شيوع بيماريها بيشتر شده و سالمندان نسبت به جوانان بيشتر در معرض ابتلا به بيماريهاى مزمن از جمله بيماريهاى قلبى-عروقى قرار دارند، در نتيجه مواجهه با بلى فارمسى افزايش دائل

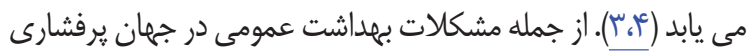

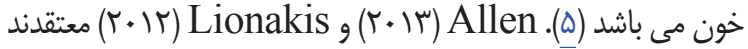
يرفشارى خون يكى از بيمارى هاى بسيار شايع در سالمندان است

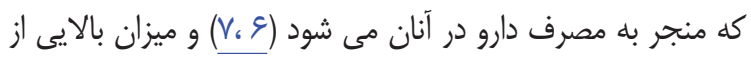
هزينه درمانى و مراقتىى را به خود اختصاص مى دهد (1). در ايران نيز و/عץ درصد افراد بالاى ها سال مبتلا به ير فشارى خون هستند (9).

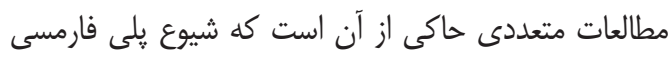
با افزايش سن، افزايش مى يابد. نتايج مطالعه ایى در كشور كره

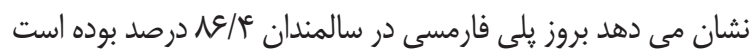
(•). بروز يلى فارمسى به دنبال بيمارى هاى مزمن در سالمندان

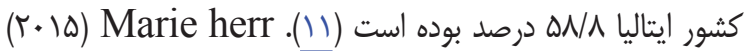

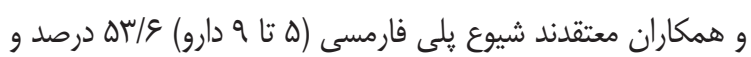
يلى فارمسى شديد (بيش از •ا دارو) ه/ ما درصد در كشور فرانسه

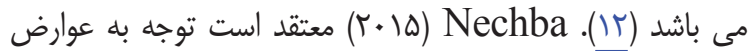
دارويى هنگام درمان به خصوص در سالمندان بايد مورد توجه قرار

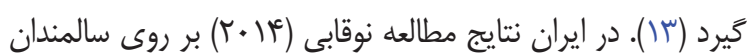
شهر كَناباد نشان داد كه بطور ميانخين أ قلم دارو در طول روز مصرف مى كردند (f(l). بايبندى به مصرف دارو يكى از مسائلى

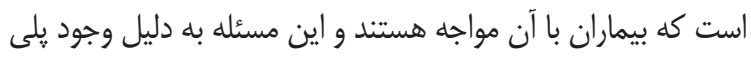

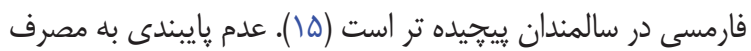
دارو در سالمندان منجر به كاهش منافع درمانى، مراجعات مكرر جهت

بسترى در بيمارستان و ويزيت هاى مكرر يزشكان مى شود (1). مدل خودمراقبتى اورم يك مدل مفهومى است كه در سال 190R توسط دورتى اليزابت اورم بر اساس اصول مراقبت از خود بايه ريزى شده است و مراقبت از خود در آن شامل فعاليت هاى فردى است تا حيات و تندرستى انسانها حفظ شود (IV). منظور از برنامه خود مراقتى فعاليت هاى تنظيم شده اي است كه باعث تثبيت توانايى ها و افزايش كارايى افراد شده و به مددجويان آموزش داده مى شود

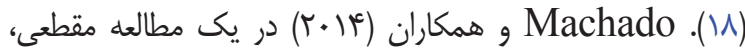




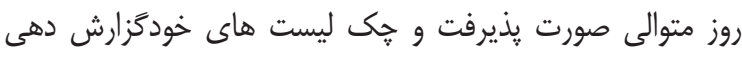

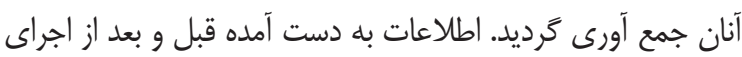
برنامه با استفاده از نرم افزار Spss إ مورد تجزيه و تحليل آمارى قرار كَرفت. سطح معنادارى كمتر از ه•/ در نظر كَرفته شد، جهت

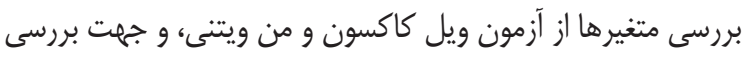

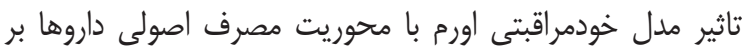

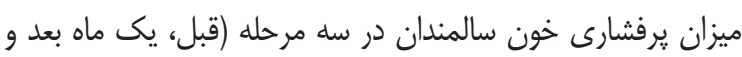

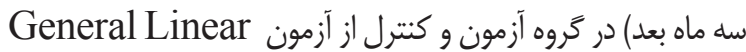
Model براى در نظر كرفتن ملاحظات اخلاقى، ابتدا هدف از اجراى

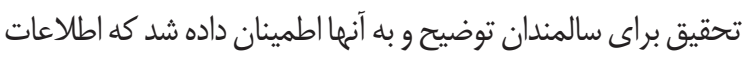
آنان محرمانه خواهد بود و اعلام كَرديد كه شركت در مطالعه اختيارى

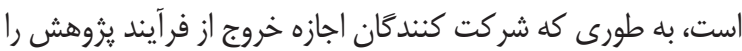

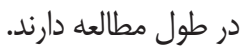

\section{كأقته ها}

تعداد •و سالمند در اين مطالعه شركت داشتند كه به دو كروه

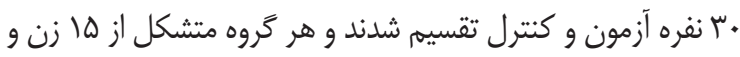

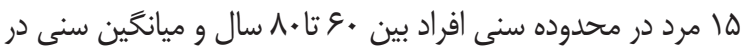
كروه آزمون و كنترل به ترتيب س. (9N و •1/99 بود. جدول شماره يك اطلاعات مربوط به همسان سازى متغيرهاى دموكرافيك را دو جران كروه آزمون و كنترل نشان مى دهد. يس از جمع آورى داده ها، ابتدا با استفاده از آزمون هاى

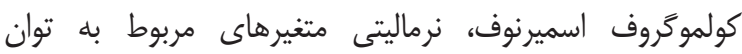
خودمراقتبى(در ابعاد آكاهى، مهارت و تمايل) و همجنين فشارخون سيستوليك و دياستوليك مورد بررسى قرار گرفت و غير نرمال بودن داده ها تاييد شد. براى بررسى ميانكين متغيرهاى مربوط به توان

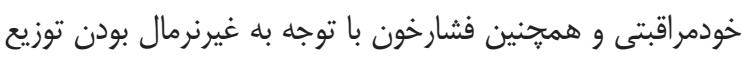
داده ها از آزمون General Linear Model استفاده شد. جدول همنال شماره r ميانكَين ابعاد مربوط به توان خودمراقبتى و فشار خون در

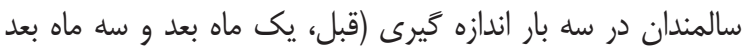

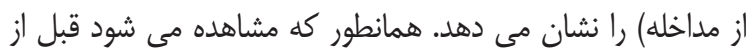

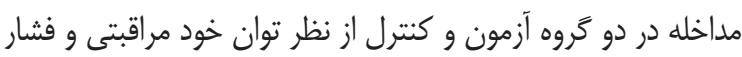
خون اختاف معنادار آمارى مشاهده نمى شود. ولى بعد از مداخله، يك ماه بعد و سه ماه بعد در كروه آزمون اختلاف معنادار آمارى لماري مشاهده مى شود، اما در كَروه كنترل اختلاف معندار آمارى مشاهده
برنامه ريزى بر اساس تشخيص هاى يرستارى: در اين مرحله، نياز سنجى بر اساس فرم بررسى و شناخت توان خودمراقبتى سالمندان مطابق الكوى اورم (نيازهاى مربوط به رشد و تكامل، نيازهاى همخانى، الكَوهاى معمول بهداشتى و نيازهاى انحراف از سلامت) انجام شد. در قسمت توان خودمراقبتى سوالات در سه بعد آكاهى،

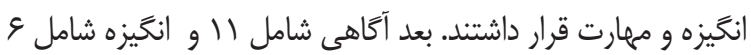

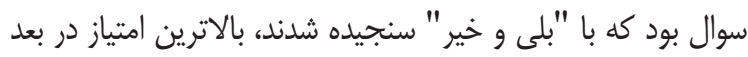

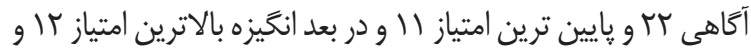
קإيين ترين امتياز צبود، بعد مهارت شامل عا سوال بود كه با "هرگز، بندرت، كاهى اوقات، اكثر اوقات و هميشه" سنجيده شد، بالاترين امتياز •مو و إيين ترين امتياز عا بود. به صورت قراردادى كسب امتياز كمتر از •ـ در بعد آكاهى، امتياز كمتر از +1 در بعد انكيزه و امتياز كمتر از هQه در بعد مهارت، كمبود توان خودمراقبتى بود. يرسشنامه هاى تكميل شده توسط سالمندان در گروه آزمون مورد تجزيه و تحليل قرار كرفتند و بر اساس اولويت به مشكلات موجود برداخته شد و مشخص شد كدام نيازهاى همخانى بر آورده و كدام نيازها هنوز

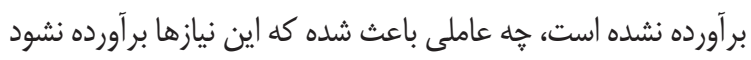

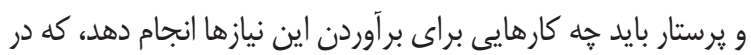

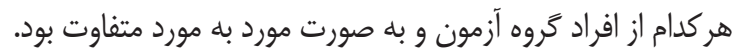
تشخيص هاى يرستارى شامل: كمبود مراقبت از خود در زمينه تغذيه و فعاليت هاى ورزشى مناسب، كمبود خودمراقبتى در برد

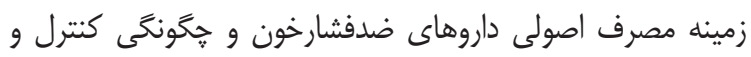

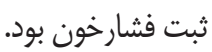
ז- طرح برنامه خودمراقبتى در قالب جلسات آموزشى: در اين مرحله نوع آموزش و كزينش و نوع سيسته يرستارى بسته به كمبودهاى اطلاعات مصرف اصولى داروها كه در مرحله اول ليست شده اند انتخاب و سالمندان در دو سيستم يرستارى آموزشى - حمايتى و جبرانى نسبى قرار خرفتند.

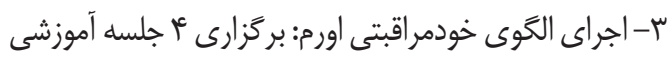
كه بر اساس نيازهاى سالمندان طراحى شده و زمان هر جلسه هأ

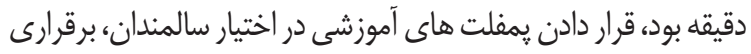
ارتباط تلفنى و حضورى در روزهاى مشخصى از هفته با سالمندان و

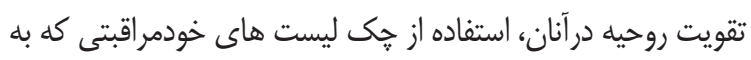
صورت ماهانه طراحى شده بود. ع- ارزشيابى: بر اساس اهداف در زمينه كاهش نيازها و و افزايش توانيى ها در انجام فعاليتهاى خودمراقبتى و از طريق سنجش التش

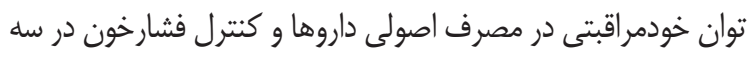


جدول (: اطلاعات دموكرافيكى در كروه آزمون و كتترل

\begin{tabular}{|c|c|c|c|c|c|c|}
\hline \multirow{2}{*}{ آزمون كاى دو } & \multicolumn{2}{|c|}{ كنترل } & \multicolumn{2}{|c|}{ آزمون } & \multirow{2}{*}{\multicolumn{2}{|c|}{ متغير }} \\
\hline & درصد فراوانى & فراوانى & درصد فراوانى & فراوانى & & \\
\hline \multirow{4}{*}{$p=\cdot / 19$} & Q. & 10 & $99 / \mathrm{V}$ & $r$. & $V \cdot-9$. & سن \\
\hline & Q. & 10 & 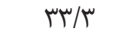 & 1. & $\Lambda \cdot-V)$ & \\
\hline & $r / \mu$ & 1 & $8 / \pi$ & r & مجرد | مجرد & \\
\hline & $v^{*} / \mu$ & r & $V r / \mu$ & r & متاهل & وضعيت تاهل \\
\hline \multirow{3}{*}{$\mathrm{p}=\cdot|\wedge|$} & $r / r$ & v & r. & 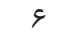 & همسرفوت شده & \\
\hline & $\varphi / \mathrm{V}$ & if & 要 & 11 & ابتدايى & \\
\hline & $r / \mathrm{V}$ & $\wedge$ & r. & 9 & راهنمايى & \\
\hline \multirow{3}{*}{$\mathrm{p}=\cdot / \mathrm{AV}$} & r. & 9 & $Y Q / V$ & $\wedge$ & دييله & ميزان تحصيلات \\
\hline & $s / \mathrm{V}$ & r & s/V & r & تحصيلات دانشكاهى & \\
\hline & 1. & r & $8 / \mathrm{V}$ & r & كم وزن & \\
\hline \multirow{3}{*}{$\mathrm{p}=\cdot \mid 9 \phi$} & $r / r$ & v & $r / r$ & 11 & نرمال & شاخص توده بدنى \\
\hline & $\Delta$. & 10 & $\$ g / V$ & זו & اضافه وزن & \\
\hline & $19 / \mathrm{V}$ & $\Delta$ & $\mid \pi / \mu$ & r & جاق ل جاق & \\
\hline \multirow{3}{*}{$\mathrm{p}=\cdot / \mu \mid$} & $r / \Gamma$ & 1 & S/V & r & بدون فرزند & \\
\hline & $1 \pi / \mu$ & r & $r g / V$ & $\wedge$ & ا تا ب فرزند & تعداد فرزندان \\
\hline & v. & r) & $9 \pi / \mu$ & 19 & ع أ ا ع فرزند & \\
\hline \multirow{4}{*}{$\mathrm{p}=\cdot|\Delta|$} & $1 \pi / r$ & i & $r / \Gamma$ & 1 & بيش از 9 فرزند & \\
\hline & $\Delta T / \mu$ & 18 & $9 \pi / \mu$ & 19 & بازنشسته (بيمه) & حمايت مالى \\
\hline & $r / \mu$ & 1 & $g / V$ & r & كميته امداد & \\
\hline & $\varphi r / \mu$ & זו & r. & 9 & خانواده & \\
\hline
\end{tabular}

جدول ז: مقايسه ميانكين هاى نمرات متغيرها در سالمندان مبتلا به فشارخون بالا در سه بار اندازه كَيرى (قبل از مداخلهيك ماه بعد و سه ماه بعد از مداخله) در دو كَروه

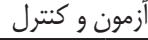

\begin{tabular}{|c|c|c|c|c|c|c|}
\hline \multirow{2}{*}{$\begin{array}{c}\mathrm{P}(\text { General } \\
\text { (Linear Model }\end{array}$} & \multicolumn{2}{|c|}{ كروه كنترل } & \multicolumn{2}{|c|}{ كروه آزمون } & \multirow{2}{*}{\multicolumn{2}{|c|}{ متغيرها }} \\
\hline & ميانكين & انحراف معيار & ميانكين & انحراف معيار & & \\
\hline $\mathrm{P}<. / . .1$ & 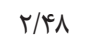 & $\mid \varepsilon / \Delta{ }^{\prime}$ & r/99 & IV/rg & قلب از مداخله & آَاهـــ \\
\hline$T=r / v q$ & r/gr & س &.$/ 91$ & TI/ S & بعد از يكى ماه مداخله & \\
\hline$D f=1$ & r/gr & $\mid$ I & . lat & M/s. & بعد از سه ماه مداخله & \\
\hline $\mathrm{P}<. / . .1$ & $\mathrm{Q} / \wedge \mathrm{V}$ & $\$ 9 / \mathrm{V}$ & $c / \mu$ & $\$ 9 / 9$ & قبل از مداخله & \\
\hline$T=r / \cdot r$ & 1.190 & $\mathrm{FV} / . \mathrm{G}$ & $\varphi / \mu$ & $9 V / \& 9$ & بعد از يك ماه مداخله & مهارت \\
\hline $\mathrm{Df}=1$ & 1.190 & $\mathrm{~F} / . \mathrm{g}$ & $\varphi / \infty$ & $g \mathrm{~V} / \mathrm{v}$. & بعد از سه ماه مداخله & \\
\hline $\mathrm{P}=\cdot / \cdot r$ & $r / \cdot V$ & $11 / \Gamma$. & $1 / \wedge r$ & $11 / 4$. & قبل از مداخله & \\
\hline$T=r / 1 \Delta$ & I/Ar & $11 / \%$. &.$/ 4$ & $11 / 9$. & بعد از يك ماه مداخله & تمايل \\
\hline$D f=1$ & $1 / A F$ & $11 / \mu$. &.$/ 1 \Lambda$ & $11 / 99$ & بعد از سه ماه مداخله & \\
\hline $\mathrm{P}<. / . .1$ & $r / \wedge 1$ & $9 \Delta / \Lambda$. & $r / M$ & $9 \Delta / \lambda \mu$ & قبل از مداخله & \\
\hline$T=r / \wedge q$ & $\varphi / M$ & $9 \Delta / \Delta \mathrm{V}$ & G/9V & $\Lambda \Gamma / \kappa$. & بعد از يك ماه مداخله & فشارخون دياستوليك \\
\hline $\mathrm{Df}=1$ & $r / M$ & $१ \otimes / \Delta V$ & 9/9V & $\Lambda T / N \mathcal{E}$ & بعد از سه ماه مداخله & \\
\hline $\mathrm{P}<\cdot / . .1$ & $s / \Delta \Delta$ & IFN/GT & $\Delta / \uparrow \Delta$ & $19 \mathrm{~V} / 1$. & قبل از مداخله & \\
\hline$T=\kappa / \mu r$ & $\Delta / g Y^{C}$ & $\mid F V / F q$ & $V|\Delta|$ & | & بعد از يك ماه مداخله & فشار خون سيستوليك \\
\hline$D f=1$ & $\Delta / g \gamma^{\circ}$ & $\mid$ IFV/rg & $V(\Delta)$ & - S & بعد از سه ماه مداخله & \\
\hline
\end{tabular}

بين دو كروه از لحاظ توان خودمراقتى تفاوت معندارى وجود دارد.

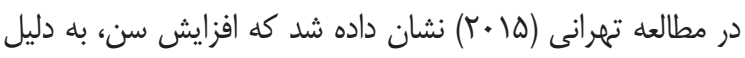

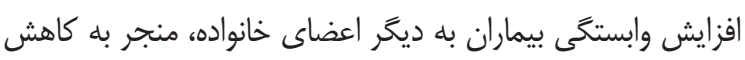

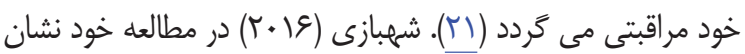
داده است كه هرجه توان خودمراقبتى در سالمندان كمتر باشد ناتوانى

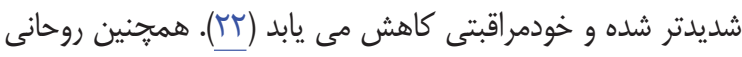

يزوهش حاضر با هدف تعيين تاثير مدل خودمراقبتى اورم با

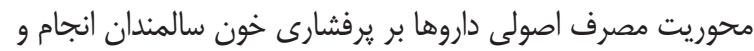

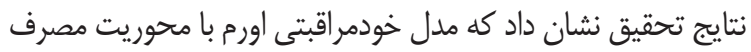

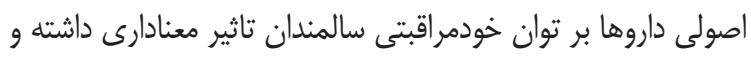


خود مراقبتى در فرآيند درمان موثر بوده است (TV). فشارخون بالا از جمله بيمارى هاى مزمن در سالمندان است دات كه نياز به مصرف دارو و انجام خودمراقبتى دارد. اين يزوهش به دانه بررسى راهى آسان، بى خطر و كم هزينه جهت مصرف اصولى و

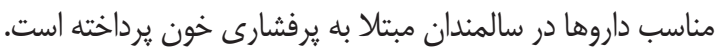
از جمله محدوديت هاى يزوهش تفاوت هاى فردى واحدهاى يُوهش از نظر روحى و روانى در باسخ به يرسشهاى يرسشنامه هاو همجنين احتمال خدشه در ير نمودن كامل جى ليَ ليست ها بود.

\section{تنيجه تيرى نهائى}

با توجه به اينكه فشارخون در سالمندانى كه مدل خودمراقبتى

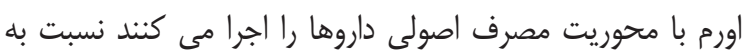
كروه كنترل كاهش مى يابد و توان خودمراقبتى افزايش مى يابد،

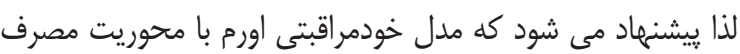
اصولى داروها در سالمندان مبتلا به يرفشارى خون در مراكز و وداني

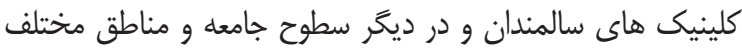
استفاده شود. بررسى تاثير مدل خودمراقبتى اورم با محوريت مصرف داف دافيكان اصولى داروها بر ساير بيمارى هاى دوران سالمندى و در ساير مراكز بهداشتى -درمانى و مراكز نكَهدارى سالمندان و همجنين در ساير

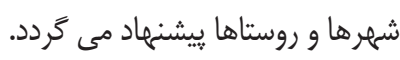

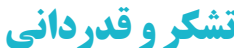

اين مقاله مستخرج از يايان نامه كارشناسى ارشد يرستارى است. يزوهشكَران مراتب سياس خود را به معاونت يزوهشى دانشكاه إناه تربيت مدرس و تمامى سالمندان عزيزى كه در اين يخروهش صادقانه

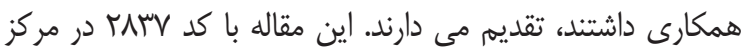
كارآزمايى بالينى ايران ثبت شده است.

\section{References}

1. World Health Organization, 'aging well' must be a global priority. News release 2017.

2. Statistical Center of Iran, Management \& Planning Organization, Status of aged Nationwide, Islamic Republic of Iran. 2016.

3. Chiang-Hanisko L, Tan Jy,Chiang Lc.Polypharmacy issues in older adults.
(10) در مطالعه خود نشان داده است كه هر خه توان خودمراقبتى سالمند كاهش يابد ناتوانى در خودمراقبتى افزايش يافته و منجر به افزايش بار مراقبتى مراقبين مى شود (سٓ). هرايى دستيابى به اين إين

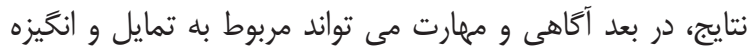
بالاى نمونه هاى مورد بررسى براى اجراى برنامه هاى عملى بر براي

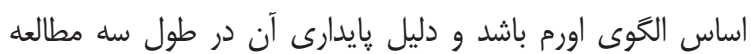
مى تواند به مربوط به يِيَيرى دقيق سالمندان با استفاده از خى

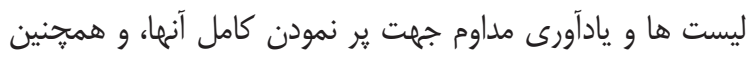

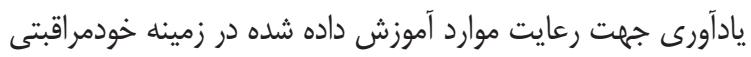

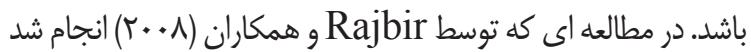
ميانگين نمره نحَرش و عملكرد مربوط به توان خودمراقبتى سالمندان

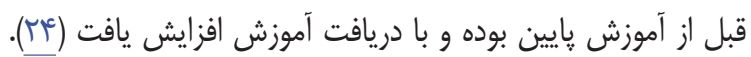

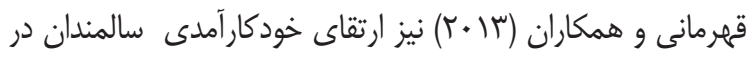
راستاى اتخاذ رفتارهاى خود مراقبتى را مهم ترين عامل بيش بيشى إنى كننده فعاليت هاى جسمانى سالمندان مى دانند (هآ). همحنين در اين مطالعه ميانكَين فشارخون در سالمندان مورد بررسى در گروه آزمون، بعد از اجراى مداخله كاهش يافته ماله است و درد طول سه ماه مداخله بايدارى وجود دارد. جرايى دستيابى به اين نتايج، مى تواند مربوط به افزايش توان خودمراقبتى به ويزه در بعد مهارت

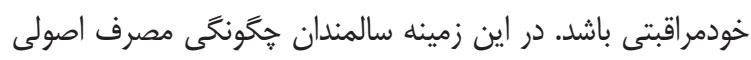
داروهايشان و همجنين لزوم كنترل مرتب فشارخون را مى آموزند و

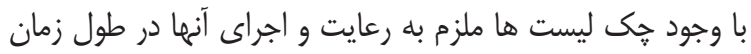

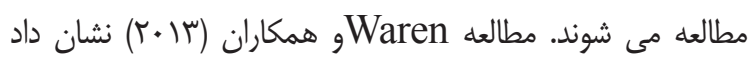

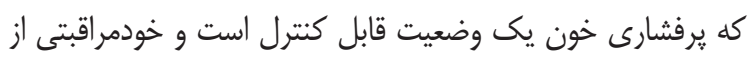

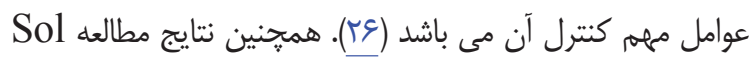
و همكاران (^+•r) در كشور هلند نشان داده است كه در مورد بيماران قلبى-عروقى اجراى مداخلات يرستارى بر مبناى رفتارهاى

Hu Li Za Zhi 2014; 61(3): 97-104.

4. Marengoni A, Angleman S, Melis R, Mangialasche F, Karp A,Garman A, et al. Aginn with multimorbidity. Aging research review 2011; 10 (14): 430-439.

5. Yadav G, Chaturvedi S, Grover VL. Prevalence, awarness, treatment and control of hypertention among the elderly in a resttlement colony of delhi. Indian heart journal 2008; 60 (4): 313- 
317.

6. Allen M, Kelly K, Fleming L. Hypertention in elderly patients. Canadian family physician 2013; 59:1921.

7. Lionakis N, Mendrinos D, Sanidas E, Favatas G, Georgopoulou M. Hypertetion in the elderly. World journal of cardiology 2012; 4 (5):135-147.

8. Fauci A,Braunwald E, Kasper D, Hauser S, Lango D, Jameson J, et al.Harrison's principles of internal medicine. 17th. New York, NY:Mcgraw-hill; 2008.2326.

9. Baghianimoghadam MH, Rahaee Z, Morovatisharifabad M, Sharifirad Gh, Andishmand A, Azadbakht L. Effects of education on self-monitoring of blood pressure based on BASNAF model in hypertention patients. Journal of research in medical sciences 2010;15 (2):70-77

10. Kim H-A, Shin J-Y, Kim M-h, Pak B-j. Prevalence and predictors of polypharmacy among Korean elderly. PloS one 2014; 9 (6):e 98043.

11. Kirchmayer U, Mayer F, Bassso M, De cristofaro R, Mores N, Cappai G. Polypharmacy in elderly :A population based cross-sectional study in Lazio. European Griatric Medicine 2016; 5 (8): 1-4.

12. Herr M, Robie J, Juliette P, Arvieu J, Ankri J. polypharmacy and frailty: prevalence, relationship, and impact on mortality in a French sample of 2350 old people. Pharmacoepidemiology and drug safty 2015; 24 (6): 637-646.

13. Nechba R, Kadiri M, Ziatni M,
Zeggwagh A, Mesfioui A. Difficulty in managin polyphamacy in the elderly : case report and review of the literature. Clinical Gerontology and Geriatrics 2015; 6 (1):30-33.

14. Delshad Noghabi A, Darabi F, Baloochi Beydokhti T, Shareinia H, Radmanesh $\mathrm{R}$. Irrational use of medicine status in elderly papulation of Gonabad. Ofogh Danesh. 2014;5(19):297-304.[persian].

15. Chiang-Haniskol, Tan JY, Chiang LC. Poly pharmacy issues in older adults. $\mathrm{Hu}$ li za zhi 2014;61(3):97-104

16. Toh MR, Teo V, Kwan YH, Raaj S, Tan SYD, Tan JZY . Association between number of doses per day,number of medications and patient'snoncompliance, and frequency of readmissions in a multiethnic Asian population. Prev Med Rep 2014; 1:43-47.

17. Memarian R. Application of nursing concepts and theories. Tarbiat modarres university press 2011:195-217.

18. Masoudi R, Mohammadi T, Ahmadi F, Hasanpour Dehkordi A. The effect of self care program education based on Orem's theory on mental aspect of quality of life in multiple sclerosis patiets. Iran journal of nursing 2009; 22 (60):53-64. [persian].

19. Machado M, Vieira M, Almeida S.Health and self-care profile of older people: A descriptive study in nursing homes, In northern Portugal. Quality in primary care 2016;24 (1):12-16.

20. Salimi F, Garmaroudi G, Hosseini M, Batebi A. Effect of self-care educational program to improving quality of life 
among elderly referred to health centers

of Zanjan. Journal of education and community health 2015; 2 (2): 28-37. [persian].

21. Tehrani H, Taghdisi MH. Community action :A strategy for health promotion. Iranian Journal of health education and health promotion 2015; 2 (4): 255-259. [Persian].

22. Shahbazi MR, Foroughan M, Roghani $\mathrm{S}$, Rhgozar M. The relationship between disability and variables of depression, cognitive status ,and morale among older people. Aging J 2016;11(1):132141.[Persian].

23. Rohani H, Eslami A, Jafari T,Koshki T ,Raei M, Abrishamkarzadeh H, Mirshahi $\mathrm{R}$, Ghaderi A. The factor affecting the burden of care of informal caregivers of the elderly in Tehran. journal of Kermansha University of Medical Sciences 2015; 18 (12): 726-733. [Persian].

24. Rajbir S, Seema G, Anita K, Paramjit C. Efficacy of nutrition counselling on knowledge, attitudes and practices of urban and rural elderly males. Studies on Home and Community Science 2008; 2 (1): 65-68.

25. Ghahramani L, Nazari M. Comparing prediction power of exercise intention and behavior based on self-efficacy and theory of planned behavior.Payesh 2013; 12 (2):99-107.[persian].

26. Waren J, Rechart B, Seymoure. The association between self-efficacy and hypertension self-care activities among African American adults. J community
health.Author manuscript;available in PMC Feb1/2013.

27. Sol BMG, Vander Graaf Y, Vander Bijl JJ, Goessens BMB, Visseren FLJ. The role of self efficacy in vascular risk factor managmentia randomized controlled trial-patient Educ couns 2008; 7 (2):191196. 